in in vitro fertilisation, but appreciable side effects are unlikely to be so rare. For instance, ovarian hyperstimulation is a known risk despite published advice that it should be preventable. ' Adequate information about possible morbidity in assisted conception is not made readily available to potentia patients, nor are the hazards apparently sufficiently acknowledged by those who deliver the treatments

Of course, the increasing success of fertility treatments is to be welcomed, but childless couples, in their desperate longing for babies, are only too ready to overlook the possible drawbacks. Fertility specialists therefore have a duty to present comprehensive information about not only the prospects of success but also the risks of assisted conception.

Warley Hospital,

BILI. TRAVERS

Brentwood, Essex CM14 5HQ

1-Hull MGR, Eddowes HA, Fahy U, Abuzeid MI, Mills MS, Cahill DJ, et al. Expectations of assisted conception for infertility. $B M 7$ 1992;304:1465-9. (6 June.)

2 Smith BH, Cooke ID. Ovarian hyperstimulation: actual and theoretical risks. BMf 1991;302:127-8. (19 January.)

EDITOR,-M G R Hull and colleagues' article confirms the positive role of assisted conception. We have several comments.

Firstly, Hull and colleagues are right to question the validity of the legal constraint on the number of eggs and embryos that can be transferred in gamete intrafallopian transfer and in vitro fertilisation. This is especially relevant to women aged 40 or above, who have a low chance of becoming pregnant after assisted conception. ${ }^{23}$ The incidence of multiple pregnancy in this age group is low even when more than three eggs or embryos are transferred, as confirmed in Hull and colleagues' and other studies. ${ }^{2}$ We have long argued for flexibility that allows a variable number of eggs or embryos to be transferred to suit the circumstances of individual couples.

Secondly, Hull and colleagues report a significantly higher pregnancy rate with gamete intrafallopian transfer than with in vitro fertilisation or high intrauterine insemination, which also confirms our experience. The difference in pregnancy rates between gamete intrafallopian transfer and in vitro fertilisation has recently narrowed owing to improvements in in vitro fertilisation and because limiting the number of eggs allowed to be transferred in gamete intrafallopian transfer has a greater effect on reducing the pregnancy rate than limiting the number of embryos transferred in in vitro fertilisation.

Thirdly, the authors' projected cumulative pregnancy rate of $82 \%$ after six attempts of in vitro fertilisation or gamete intrafallopian transfer is encouraging, but even better results could have been obtained sooner, and with fewer attempts, if cryopreservation of embryos had been available.

The pregnancy rate after replacement of thawed embryos in our centre in 1991 was $28 \%$ per frozen embryo replacement ( 22 out of 79 cycles). During the same year 275 cycles of gamete intrafallopian transfer and 263 cycles of in vitro fertilisation were performed. The clinical pregnancy rate was $32 \%$ after gamete intrafallopian transfer and $24 \%$ after in vitro fertilisation $(40 \%$ and $26 \%$ respectively for women under 40). Including frozen embryo replacement results in a projected cumulative pregnancy rate of $60 \%$ for gamete intrafallopian transfer and $52 \%$ for in vitro fertilisation after a single superovulation egg retrieval cycle $(69 \%$ and $54 \%$ respectively for women under 40 ).

Cryopreservation of suitable embryos should be an integral part of assisted conception programmes to increase cumulative pregnancy rates and reduce costs and the need for repeated superovulation and egg retrieval.

TALHA AL-SHAWAF

IAN CRAFT

London Fertility Centre and Medicraft Services,

London WIN IAF
I Hull MGR, Eddowes HA, Fahy U, Abuzeid MI, Mills MS, Cahill DJ, et al. Expectations of assisted conception for infertility. BMJ 1992;304:1465-9. (6 June.)

2 Craft IL, Ah-Moye M, Al-Shawaf T, Fiamanya W, Lewis $P$ Robertson D, et al. Analysis of 1071 GIFT procedures - the Al-Se for a fexible approach to treatment. Lancet 1988;1:1094-8. The infuence of o, Guirgis $R$, Harper J, Sancis $M$, The inflence of ovarian response on gamete intrafallopia transfer outcome in older aged women. Hum Reprod (in press).

\section{Cancer chemotherapy and fertility}

EDIToR,- When quality of life during and after cancer chemotherapy is being considered ${ }^{\prime}$ the loss of gonadal function, with the consequence of infertility, should also be taken into account. Increasing numbers of male and female patients are surviving chemotherapy for cancer in childhood and the reproductive years. Reproductive capability may be a major factor when contemplating their prospective quality of life.

Research is in progress at the Royal London Hospital to determine the precise effects of chemotherapy on fertility. Alkylating agents, for instance, have a substantial deleterious action on the gonads, leading to the possibility that chemotherapeutic substitution may give a better prognosis for fertility without prejudicing the outcome of treatment.

We believe that fertility is an important factor in the quality of life and should be discussed during counselling before and after treatment. It should be taken into account when deciding on the timing of chemotherapy and the protocol. If gonada damage is deemed inevitable then, when possible, gamete preservation should be offered.

NIGEL F PERKS ADRIAN M LOWER STEPHEN M KELSEY

Royal London Hospital Trust,

London E1 1BB

1 Byrne M. Cancer chemotherapy and quality of life. BMF 1992;304:1523-4. (13 June.)

\section{Steroid receptors in early breast cancer}

EDITOR, - In reviewing recent developments in the management of early breast cancer $R$ D Rubens, discussing risk evaluation, plays down the role of measurement of steroid receptor concentrations. Nevertheless, several reports have shown steroid receptor concentrations to have prognostic value in early, node negative breast cancer treated without adjuvant therapy..$^{2-4}$

We have measured, by enzyme immunoassays, oestrogen receptor and progesterone receptor concentrations in tumours $(61 \% \leqslant 2 \mathrm{~cm})$ of 130 patients entered into a prospective randomised trial comparing different regimens of radiotherapy in women with clinically node negative early breast cancer ( $\leqslant 5 \mathrm{~cm}$ diameter) treated by conservative surgery. All patients in this trial received adjuvant tamoxifen, being further randomised to either continuous treatment or treatment for two years only; this is particularly relevant when the prognostic value of hormone receptor status is being considered.

After a median follow up of 18 (range 0-41) months our results show that, with a cut off of $20 \mathrm{fmol} / \mathrm{mg}$, negative status for both steroid receptors, but particularly oestrogen receptors, is significantly associated with early recurrence (table). All the patients who developed recurrence were taking tamoxifen at the time, and the length of follow up for patients who were negative and positive for oestrogen receptors was similar. Of other available risk factors (size and grade of tumour, menopausal status, $\mathrm{pS} 2$ protein), only the grade of the tumour $\left(\chi^{2}=6.6, p<0.02, n=96\right)$ and
Number of women who were disease free or had recurrence of breast cancer at follow up according to oestrogen receptor and progesterone receptor status

\begin{tabular}{lcccccc}
\hline & \multicolumn{2}{c}{$\begin{array}{c}\text { Oestrogen } \\
\text { receptors }\end{array}$} & & \multicolumn{2}{c}{$\begin{array}{c}\text { Progesterone } \\
\text { receptors }\end{array}$} \\
\cline { 2 - 3 } & Negative & Positive & & Negative Positive \\
\hline Recurrence $(\mathrm{n}=19)$ & 14 & 5 & & 13 & 6 \\
Disease free $(\mathrm{n}=111)$ & 22 & 89 & & 42 & 69 \\
\hline Total & 36 & 94 & & 55 & 75 \\
& $\chi^{2}=20 \cdot 9, \mathrm{p}<<0 \cdot 001$ & & $\chi^{2}=5 \cdot 0, \mathrm{p}=0 \cdot 025$
\end{tabular}

the oestrogen regulated pS2 protein concentration (radioimrunoassay, cut off $1 \mathrm{ng} / \mathrm{ml} ; \chi^{2}=5 \cdot 3$, $\mathrm{p}<0.05, \mathrm{n}=83$ ) were significant. Of the eight deaths related to cancer, six were in women who were negative for both oestrogen receptors and progesterone receptors and all were in women who were negative for at least one steroid receptor.

As Rubens points out when discussing adjuvant therapy, oestrogen receptor concentration has recently been shown to correlate highly significantly with a reduction in annual odds of death with adjuvant tamoxifen. ${ }^{5}$ Our early results are consistent with this observation and suggest that markers of a functionally intact oestrogen response pathway ( $P R$ and pS2) may also have a role in the evaluation of risk. We believe, therefore, that measurement of steroid receptor concentrations in early breast cancer gives valuable prognostic information, particularly for the increasing number of patients treated with adjuvant tamoxifen

P S STONELAKE

Department of Surgery,

Dudley Road Hospital,

Birmingham B18 7QH

Department of Surgery,

Birmingam B15 2TH

P R BAKER

P G BAKER

J M MORRISON

D SPOONER

West Midlands Breast Cancer Group,

Clinical Trials Unit,

Queen Elizabeth Hospital,

Birmingham B15 2TH

1 Rubens RD. Management of early breast cancer. BM 1992;30 1361-4. (23 May.)

2 Thorpe SM, Rose C, Rasmussen BB, Mouridsen HT, Bayer T, Keiding N. Prognostic value of steroid hormone receptors: multivariate analysis of systemically untreated patients with node negative primary breast cancer. Cancer Res 1987;47. 6126-33.

3 Clark GM, McGuire WL. The clinical usefulness of oestrogenreceptor and other markers of hormone dependence. Proceedreceptor and other markers of hormone dependence.
ings of the Royal Society of E dinburgh 1989;958:145-50.

4 Chevallier B, Mosseri V, Dauce JP, Basuyan JP, Bastit P, Julien $\mathrm{JP}$, et al. A prognostic score in histological node negative breast $J \mathrm{P}$, et al. A prognostic score in histolo

5 Early Breast Cancer Trialists' CoHaborative Group. Systemic treatment of early breast cancer by hormonal, cytotoxic, or immune therapy. Lancet 1992;339:1-15, 71-85.

\section{Hyponatraemia in children}

EDIroR, - Allen I Areiff and colleagues emphasise the need for greater awareness that serious electrolyte disturbances can occur in apparently healthy children.' This has important implications as early treatment can appreciably improve their outcome. We treated a previously healthy 11 year old child who suffered serious neurological complications due to water intoxication during a prolonged swimming session with a mixed age group.

On the evening before his admission he trained as a member of the local lifesaving club; swimming for about three hours. During this time he inadvertently swallowed "a lot of water," being splashed by the adult members of the team. Soon after returning home he started vomiting and became agitated and progressively obtunded. There was no history of exposure to toxins or drugs, nor was there any family history of a seizure disorder. 
On admission he was semiconscious and scored 9 on the Glasgow coma score. He showed writhing movements of his hands and subsequently had a short tonic-clonic fit. Both his plantar responses were extensor, but the remainder of the physica examination gave normal results. Initial investigations showed a serum sodium concentration of $121 \mathrm{mmol} / \mathrm{l}$, potassium $3.9 \mathrm{mmol} / \mathrm{l}$, and chloride $90 \mathrm{mmol} / \mathrm{l}$ with a creatinine concentration of $54 \mu \mathrm{mol} / \mathrm{l}$ and osmolarity of $254 \mathrm{mmol} / \mathrm{l}$. A com puted tomogram of the brain and results of examination of cerebrospinal fluid were normal. Unfortunately, a urine sample was not obtained at the time of admission, but it was presumed that he was a victim of near drowning; he was treated with fluid restriction over the next 72 hours, and his clinical state and biochemical profile returned to normal.

This patient must have ingested at least $1 \cdot 2$ 1.5 litres of pool water during his swimming lesson to have lowered his serum sodium concentration to $121 \mathrm{mmol} / \mathrm{l}$, assuming a previous serum sodium of $140 \mathrm{mmol} / \mathrm{l}$. Such a rapid ingestion of dilute liquid can result in an abrupt lowering of serum osmolarity with a resultant shift of water into intracellular brain tissue.

A doctor faced with a history compatible with near drowning or possible aspiration of water must consider the diagnosis of acute water intoxication.

MICHAEL WRIGHT PADMANI DE SILVA

SUNIL SINHA

Department of Paediatrics,

Dephespital

1 Arieff AI, Ayus JC, Fraser CL. Hyponatraemia and death or permanent brain damage in healthy children. $B M$ 1992;304:1218-22. (9 May.)

EDITOR,-Allen I Arieff and colleagues are correct to draw attention to the dangers of postoperative hyponatraemia in paediatric patients, but their suggested treatment with hypertonic saline is hazardous. ${ }^{1}$ Use of hypertonic saline to correct postoperative hyponatraemia rapidly has been reported to cause osmotic demyelination in paediatric patients ( $<16$ years). ${ }^{23}$ In these cases the serum sodium concentration was corrected by a maximum of $15 \mathrm{mmol} / \mathrm{l}$ in the first 24 hours, but use of hypertonic saline may result in even greater changes in sodium concentration as the rate of corre ion is difficult to control.

The main danger in acute severe hyponatraemia is brain swelling resulting in herniation. If the brain is not herniated hypertonic saline is probably unnecessary. If it is herniated hypertonic saline is ineffective as one cannot give enough to result in appreciable water shifts in the time necessary.

I suggest that if a patient has severe postoperative hyponatraemia with relatively minor symptoms then hypotonic fluids should be stopped and homoeostatic mechanisms allowed to correct the sodium concentration. Only if this fails to occur should more aggressive treatments be considered. If the brain is herniated standard treatment with mannitol and hyperventilation to reduce intracranial pressure should be initiated.

SIMON J ELLIS

Department of Clinical Neurology,

\section{Radcliffe Infirmary,}

Oxford OX2 6HE

1 Arieff AI, Ayus JC, Fraser CL. Hyponatraemia and death or permanent brain damage in healthy children. $B M$ 1992;304:1218-22. (9 May.)

2 Chercover DJ, Norman MG. Central pontine myelinolysis in a 6 month old infant with rapidly corrected hyponatremia.

3 Silverstone B-Z, Ronen S, Steinberg A, Berson D. A metabolic aspect of transient bilateral external ophthalmoplegia. Metab aspect of transient bilateral external

4 Ellis SJ. Correction of hyponatremia and its relation to brain damage. $N$ Engl F Med 1988;318:1335.

5 Stern AE, Coxon RV. Osmolarity of brain tissue and its relation to brain bulk. Am $\mathcal{F}$ Physiol 1964;204:1-7.

\section{Treatment of malignant intracranial germ cell tumours}

EDITOR, - In reviewing the recent developments in the treatment of germ cell tumours G M Mead suggests that treating primary malignant intracranial teratoma with chemotherapy alone is associated "with a substantial chance of cure." This view is not supported by the available data as intracranial malignant teratoma carries a poor prognosis despite treatment with cisplatin containing chemotherapy. ${ }^{2-4}$ Only one patient with malignant teratoma was described in the paper that Mead refers to, and she died three months after the start of treatment.

Five year survival rates of around $33 \%$ have been reported for patients with these tumours treated with either cranial or craniospinal irradiation. ${ }^{6}$ Combined modality treatment, with craniospinal irradiation after cisplatin based chemotherapy, seems to be necessary to improve the results in this group of tumours. ${ }^{47} \mathrm{~A}$ literature review suggests that chemotherapy alone may suffice when the tumour is made up exclusively of choriocarcinomatous elements.

Although the short term and long term deleterious sequelae of craniospinal irradiation are well recognised, ${ }^{8}$ the available data support the view that the main concern in these patients is still to prolong survival rather than minimise the late effects of treatment. ${ }^{9}$ The improved overal outlook for patients with malignant germ cell tumours is not seen in this subgroup of patients.

S SENAN

Cancer Research Campaign Beatson Laboratories,

Department of Radiation Oncology,

Glasgow University,

Glasgow G61 $1 \mathrm{BD}$

1 Mead GM. Testicular cancer and related neoplasms. $B M J$ 1992;304:1426-9. (30 May.)

2 Kida Y, Kobayashi T, Yoshida J, Kato K, Kageyama N. Chemotherapy with cisplatin for AFP-secreting germ cell tumors of the central nervous system. $\mathcal{f}$ Neurosurg 1986;65:470-5.

3 Dearnaley DP, A'Hern RP, Whittaker S, Bloom HG. Pineal and CNS germ cell tumors: Royal Marsden experience 1962-1987. Int F Radiat Oncol Biol Phys 1990;18:773-81.

4 Senan S, Rampling R, Kaye SB. Malignant pineal teratomas: a report on 3 cases and the case for craniospinal irradiatio following chemotherapy. Radiother Oncol 1991;22:209-13.

5 Smith DB, Newlands ES, Begent RHJ, Rustin GJS, Bagshaw KD. Optimum management of pineal germ cell tumours. Clin Oncol 1991;3:96-9.

6 Matsutani M, Takakura K, Sano K. Primary intracranial germ cell tumours: pathology and treatment. Prog Exp Tumor Res 1987;30:307-12.

7 Hoffman H, Otsubo H, Hendrick B, Humphreys RP, Drake JM, Becker LE, et al. Intracranial germ-cell tumors in childre f Neurosurg 1991; 74:545-51.

8 Packer RJ, Meadows AT, Rorke LB, Goldwein JL, D'Angio G. Long-term sequelae of cancer treatment on the central nervous Long-term sequelae of cancer treatment on the central nert

9 Allen JC, Ho JK, Packer RJ. Neoadjuvant chemotherapy for newly diagnosed germ-cell tumors of the central nervous system. F Neurosurg 1987;67:65-70.

\section{Diarrhoea}

EDITOR, - In A J M Watson's article on diarrhoea, no mention is made of the role of notification or infection control in the management of infectious cases.

Clinicians managing cases of dysentry (bacilliary or amoebic) or food poisoning have responsibility under the Public Health Act 1984 and Public Health (Infectious Disease) Regulations 1988 to notify them to their local authority. Notifications by certificate or by certificate and telephone in the case of infected food handlers should be made to the proper officer, either the medical officer of environmental health or consultant in communicable disease control. Cases managed in the community should be nursed with gastroenteric precautions. Those admitted to hospital should be barrier nursed in single cubicles, the local infection control policy consulted, and the infection control team informed. Food handlers, health care and nursery staff, children aged less than 5 years, and people unable to implement good standards of personal hygiene (for example, mentally ill, handicapped, or infirm elderly people) pose a special risk of spreading infection and may require temporary exclusion from work or school as appropriate. Authoritative guidelines on the subject have recently been published

Control of infection is often overlooked in the management of infectious diarrhoea, with potentially serious and costly implications for the hospital and community. After all, prevention is surely better than cure.

Department of Medical Microbiology,

A J HAY

\section{King's College Hospital,}

London SE5 9RS

\section{Watson AJM. Diarrhoea. BMf 1992;304:1302-4. (16 May.) \\ 2 Public Health Laboratory Service Salmonella Sub-Committee. Notes on the control of human sources of gastrointestina infections, infestations and bacterial intoxications in the} United Kingdom. Communicable Disease Report 1990;suppl 1.

\section{Reversing vasectomy}

Editor,-Anjan K Banerjee and Alan Simpson suggest that reversal of vasectomy leads to patency in $80-90 \%$ of cases but only a $30-40 \%$ chance of pregnancy, and they list a number of potential causes of functional failure.' They also suggest that reversal is requested by only a small number of men $(3 \%){ }^{2}$

Experience in our donor insemination programme suggests that regret about vasectomy may be more common than suggested merely by the number requesting surgical reversal. Between 1984 and 1991,160 of 1024 couples requested donor insemination treatment because of a previous vasectomy. Fewer than $2 \%$ of these couples were in the same relationship as when the vasectomy had been carried out. In $25 \%$ surgery had not been considered and no attempt at reversal had been made.

More importantly, sperm antibodies may account for a large part of the discrepancy between patency and conception rates. Of those who had had reversal attempted and spermatozoa subsequently seen on microscopical examination of semen, 85\% (19/22) had significant titres of sperm antibodies in their seminal plasma. Whether these antibodies develop as a result of the original vasectomy or after its reversal is not clear, but we would strongly advocate screening for seminal plasma sperm antibodies before vasovasostomy is undertaken to help decide whether surgery is appropriate

An alternative would be to at least offer cryopreservation and banking of semen to men who are considering vasectomy. This would certainly give a more realistic chance of fatherhood for the roughly $5 \%$ of men who later regret their decision.
D J CAHILL
$S$ HARRIS
P G WARDLE
W C L FORD
C COULSON
M G R HULL

Department of Obstetrics and Gynaecology,

Bristol Maternity Hospital,

Bristol BS2 8EG

1 Baneriee AK, Simpson A. Reversing vasectomy. $B M 71992 ; 304$ :
1130 . (2 May.)
2 Howard G. Who asks for vasectomy reversal and why? $B M f$
$1982 ; 285: 490-2$.

\section{Monitoring lithium treatment}

EDIToR,-We confirm the findings of $\mathrm{J} S \mathrm{E}$ Hellewell and Elizabeth Wyn Pugh, whose audit of lithium use showed deficiencies in pretreatment physical assessment and documentation of information given to the patient.' 